Hubert Koller, ${ }^{\star}\left(\right.$ a) Soumya Senapati, (a) Jinjun Ren, (a) Tobias Uesbeck, ${ }^{(a)}$ Vassilios Siozios, ${ }^{(a)}$ Michael Hunger, ${ }^{(b)}$ Raul F. Lobo ${ }^{(c)}$

\title{
Post-Synthesis Conversion of Borosilicate Zeolite Beta to an Aluminosilicate with Isolated Acid Sites: A Quantitative Distance Analysis by Solid-State NMR
}

\section{Supporting Information}

a) Institute of Physical Chemistry, University of Münster, Corrensstr. 28/30, 48149

Münster, Germany

b) Institute of Chemical Technology, University of Stuttgart, 70550 Stuttgart, Germany

c) Center for Catalytic Science and Technology, Department of Chemical and Biomolecular Engineering, University of Delaware, Newark, DE 19716, USA

Table S1: adsorption data of isopropylamine

Figure S1: XRD data of various samples of route $A$

Figure S2: XRD data of various samples of route B and C

Figure S3: ${ }^{27} \mathrm{Al}$ MAS NMR of various samples after Al insertion

Figure S4: temperature-dependent propene mass flux 


\begin{tabular}{|c|c|c|c|c|}
\hline & $\begin{array}{l}\left.\right|^{H^{+}} \mid[S i, B- \\
\text { BEA }]^{A}\end{array}$ & $\begin{array}{c}\left|\mathrm{H}^{+}\right|[\mathrm{Si}, \mathrm{Al}, \mathrm{B}- \\
\mathrm{BEA}]^{\mathrm{A}}\end{array}$ & $\begin{array}{c}\left|\mathrm{Ca}^{2+}, \mathrm{H}^{+}\right|[\mathrm{Si}, \mathrm{Al}, \mathrm{B}- \\
\text { BEA }]^{\mathrm{B}}\end{array}$ & $\left|\mathrm{H}^{+}\right|[\mathrm{Si}, \mathrm{A} \mid-\mathrm{BEA}]^{\mathrm{C}}$ \\
\hline $\begin{array}{l}\text { m (zeolite) / } \\
\text { mg }\end{array}$ & 10.59 & 10.96 & 10.06 & 10.22 \\
\hline $\begin{array}{l}\text { adsorbed IPA } \\
\text { / mg }\end{array}$ & 1.88 & 1.75 & 1.62 & 1.64 \\
\hline $\begin{array}{l}\text { physisorbed } \\
\text { IPA / mmol.g-1 }\end{array}$ & 3.00 & 2.39 & 2.12 & 1.93 \\
\hline $\begin{array}{l}\text { chemisorbed } \\
\text { IPA / mmol.g-1 }\end{array}$ & 0 & 0.31 & 0.60 & 0.78 \\
\hline
\end{tabular}

Table S1: Adsorption analyses of isopropylamine in the various zeolites. 

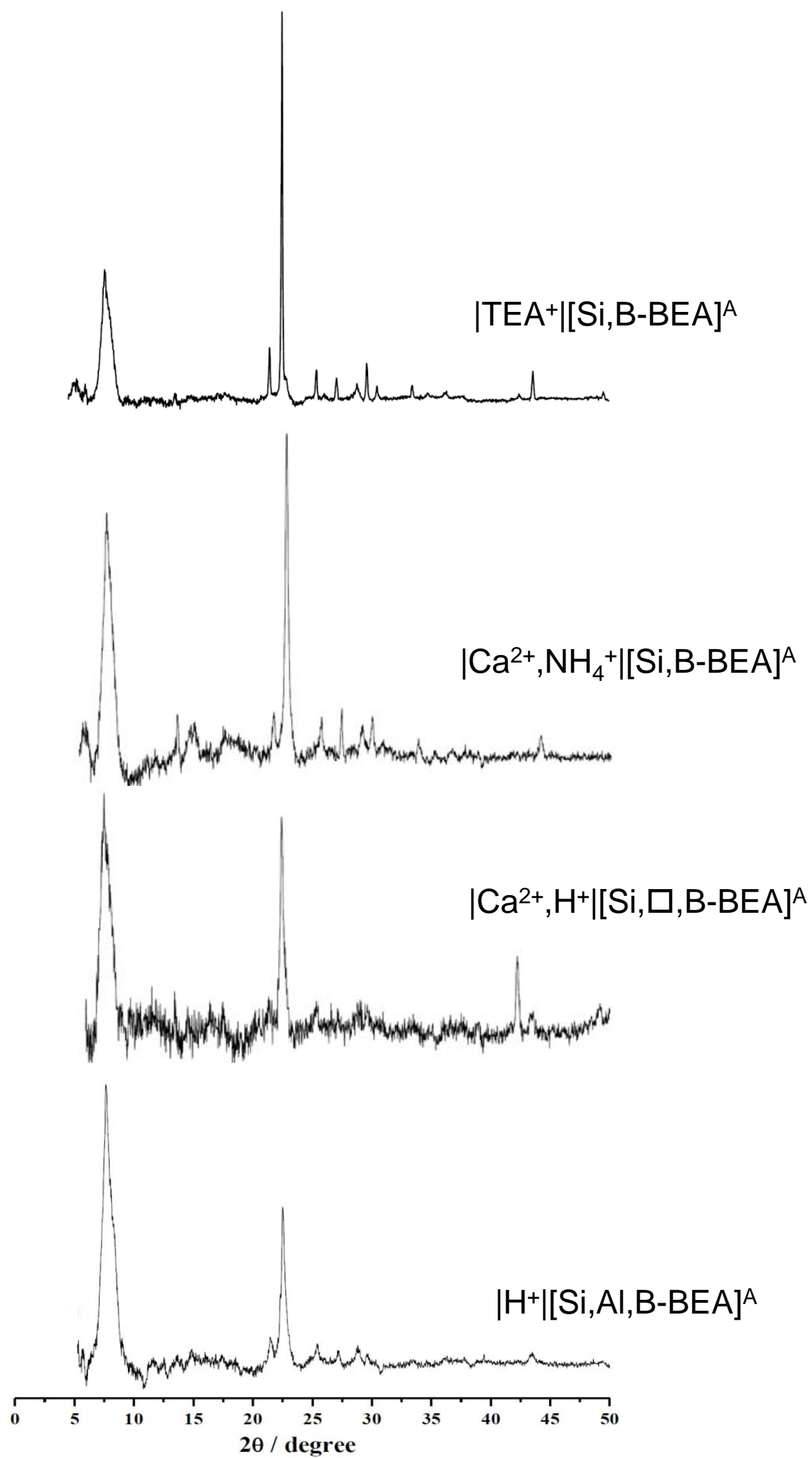

Figure S1: XRD data of various samples of route $A$ 


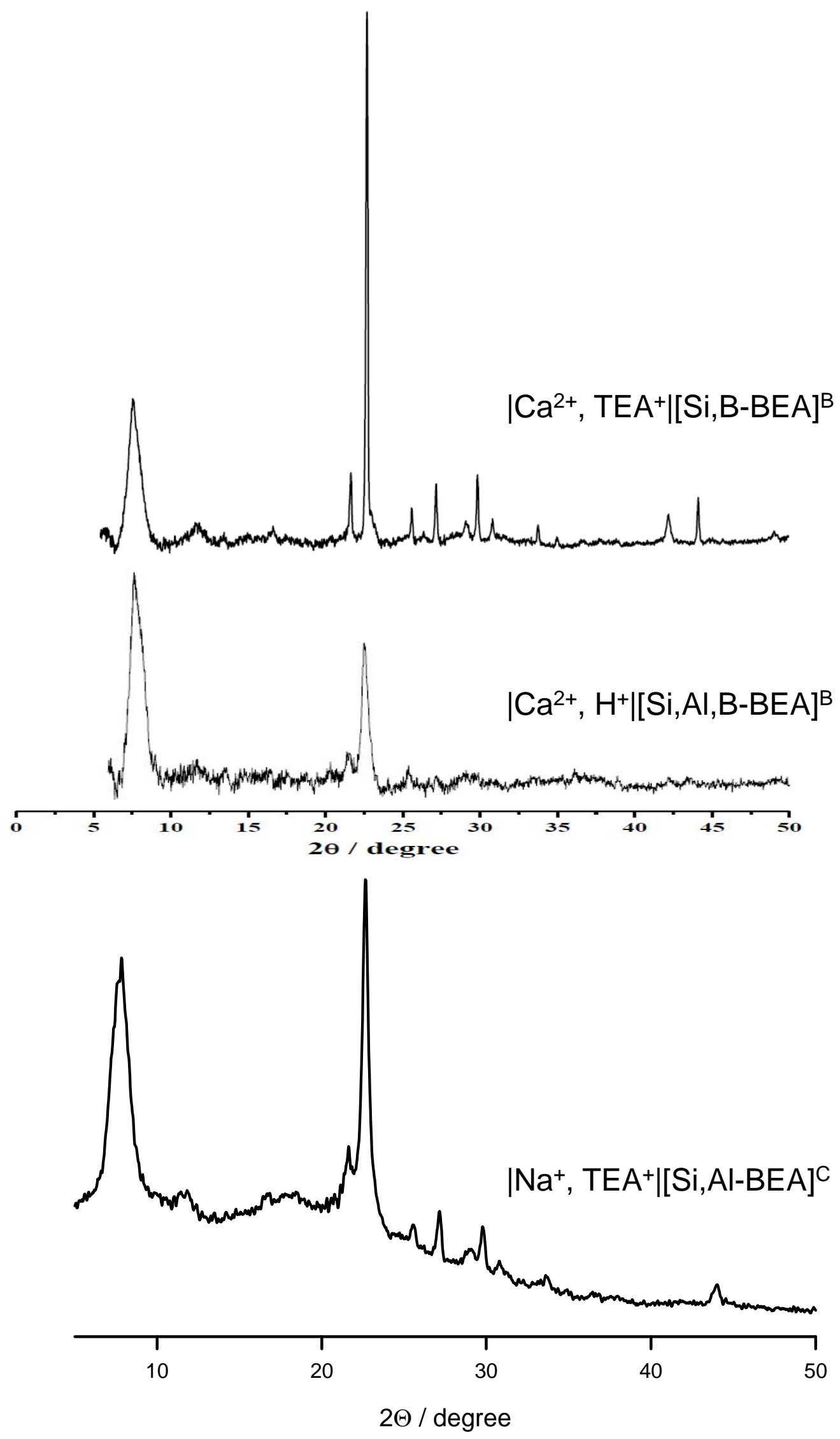

Figure S2: XRD data of various samples of route $B$ and C; broad peaks between 10 and 20 degrees are from sample holder 


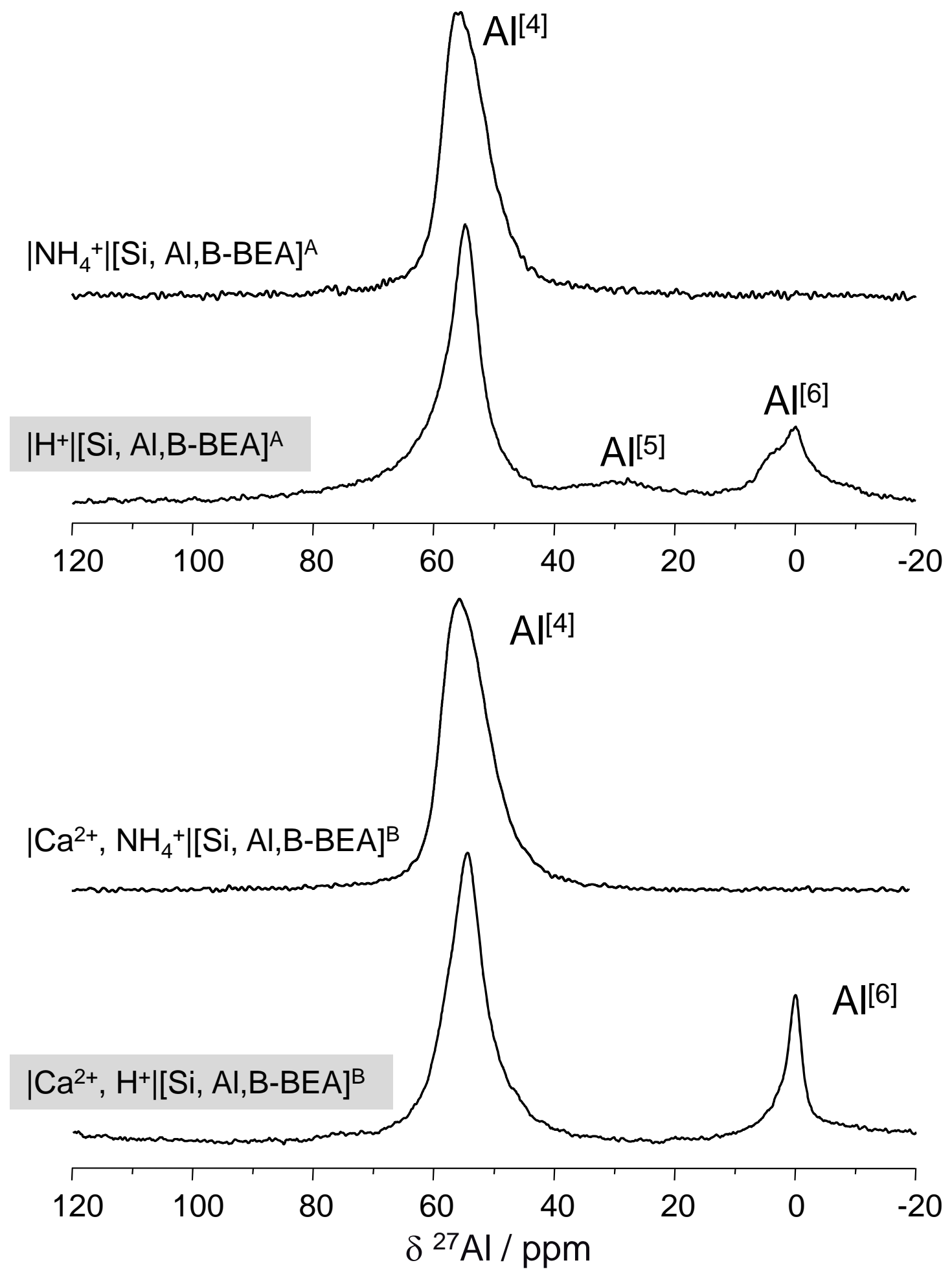

Figure S3: ${ }^{27} \mathrm{Al}$ MAS NMR of various samples after Al insertion 


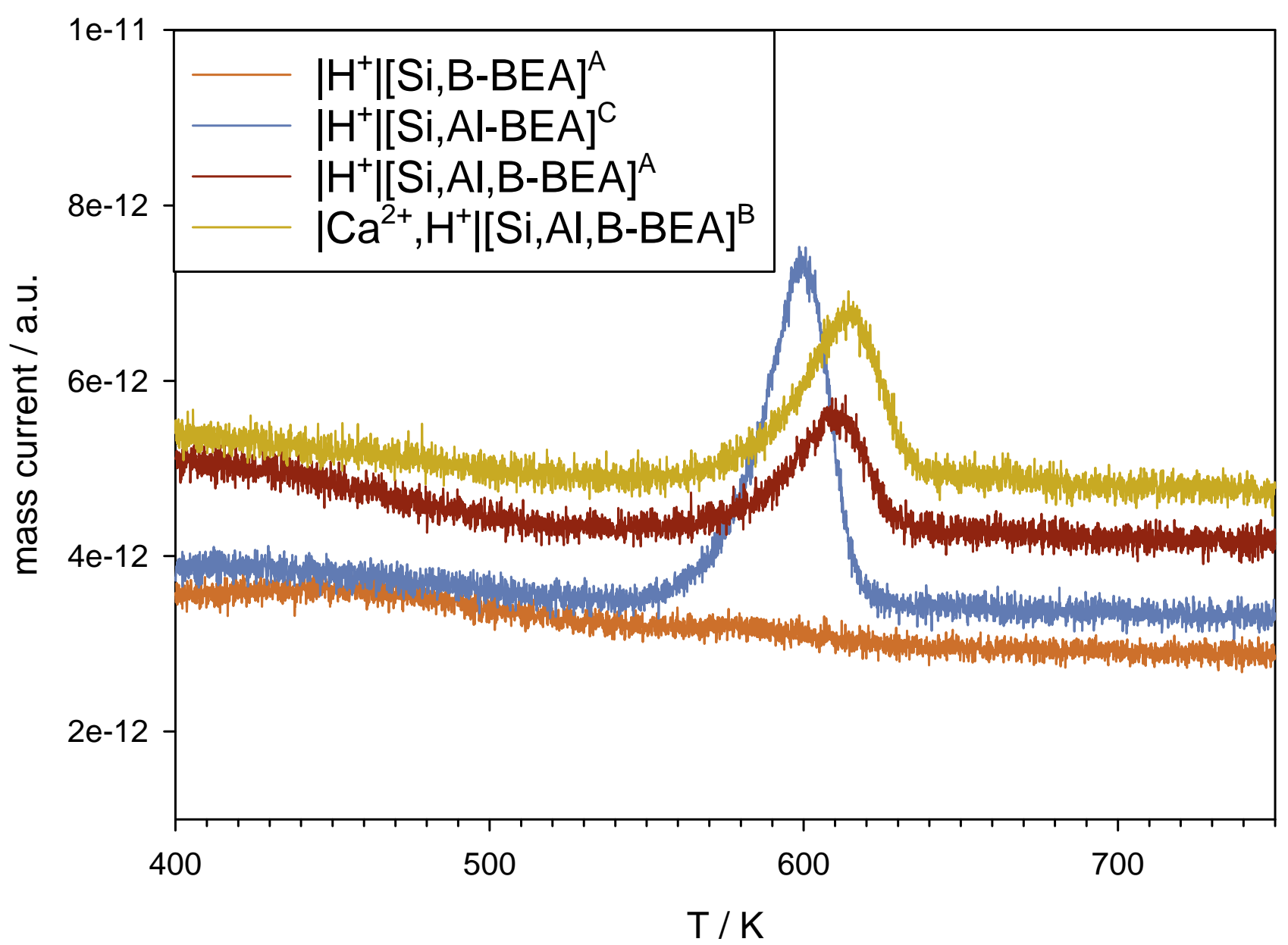

Figure S4: temperature-dependent flux of propene $(\mathrm{m} / \mathrm{e}=39)$ as observed in the mass spectrometer after heating in the TGA 